\title{
Analysis of Pressure Characteristics of Tube-contained Raw Material Pipeline Hydraulic Transportation under Different Discharges
}

\author{
Jun Wang ${ }^{1,2}$, Xihuan Sun ${ }^{1, *}$ and Yongye $\mathrm{Li}^{1}$ \\ ${ }^{1}$ College of Water Resource Science and Engineering, Taiyuan University of Technology, Taiyuan 030024, China \\ ${ }^{2}$ Shanxi Digital Water Center, Taiyuan 030002, China \\ ${ }^{*}$ Corresponding author
}

\begin{abstract}
Tube-contained raw material pipeline hydraulic transportation is a new energy-saving and environmentally -friendly technique of piped hydraulic transportation. In the paper, some pressure characteristics of tube-contained raw material pipeline hydraulic transportation under different discharges were mainly researched. The results show that there was a direct proportional linear relationship between the discharge and the average velocity of the piped carriage. Additionally, it was discovered that the fluidal pressure change of each cross section change in the pipe while the piped carriage was moving were closely connected with discharges. These conclusions will be of great important practical significance to the improvement of the technique of tube-contained raw material pipeline hydraulic transportation.
\end{abstract}

Keywords-hydraulic transportation; pressure characteristics; discharge; piped carriage

\section{INTRODUCTION}

With the rapid development of social economy, the population is growing dramatically, causing serious environmental pollution, a significant reduction in arable land, traffic congestion and accidents. These problems have gradually become a bottleneck, which seriously limits the rapid, steady, sustainable economic development. However, the main causes of city traffic congestion and air pollution is to ground vehicles as the main mode of city distribution logistics and private cars increasing ownership. It can be predicted that future traffic will give caused unbearable burden to the land and space resources, depending on the continued improvement of China's economy [1].

The development of freight transportation through pipeline and the freight transportation system through underground in the urban area is a new idea, It is a landmark research and development field which make today's freight transportation through pipeline only can distribution of liquids (including transportation and supplying of commodity and the municipal solid waste, etc.), gases and other substances extends to be distribution of solids, and put a vehicle on the ground as the main form of distribution logistics turning to the freight transportation through pipeline and the freight transportation system through underground. Through the implementation of underground pipes logistics, not only can greatly reduce environmental pollution in cities, but also can greatly improve the speed and efficiency of logistics and distribution. Based on the advantages, we propose a new method of transport material products - the piped hydraulic transportation of tube-contained raw material.

Tube-contained raw material pipeline hydraulic transportation is a new technique. In this technique, the liquid is used as a carrier, and bulk material (solid or liquid) is filled and sealed in a cylinder-shaped carriage. It is a transportation mode which uses the closed pipeline to transport material [2-4].

Compared with the traditional piped hydraulic transportation, Its originalities are as follows: firstly, material is directly put into the tube so that transportation of pure material is achieved; moreover, cylindrical braces are respectively installed at two ends of the barrel with the angular interval is $120 \mathrm{o}$ and universal ball bearings are installed at the ends of the braces. On the one hand, it changes the form of friction between the piped carriage and the inner walls of the pipeline, that is, sliding friction is changed into rolling friction so that transportation resistance is reduced. On the other hand, the axis of the barrel and the axis of the pipe are coincident, and they keep running along the same axis when the piped carriage is static or motional in the pipe. In this paper, the barrel used to contain material and its subsidiary components (cylindrical brace and the universal ball bearing, etc.) are defined as the piped carriage. The structure of the piped carriage is shown in Figure I.

Moving behaviors of the piped carriage and hydraulic characteristics of the fluid in the pipe are closely related to discharges. In this paper, the velocity changes of the piped carriage under different conditions of discharges, as well as the corresponding fluid pressure changes in the pipeline and energy consumption changes with the discharge were mainly researched.

\section{TESt Layout AND DESIGN}

The test system [5-6] consists of four parts: flow regulation and measurement system, delivery and receiving system, test pipeline and test system. Test pipeline is made of plexiglass, and the pipe sections are sealed and connected by the flange. Water supply is firstly supplied by a pump from an underground reservoir into the water-supply steel pipe, then its discharge is adjusted by the gate valve, and it enters the plexiglass pipeline. And hydraulic factors in the pipeline in the test tube sections are measured. Finally, the water flows through the outlet sump to the underground reservoir to form a 
closed circulation loop. The test system is showed in Figure II.

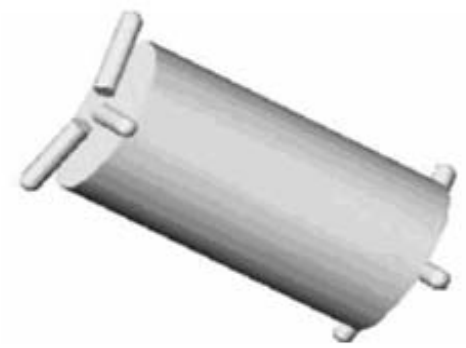

There are many factors influencing hydraulic transportation characteristics, including flow, load, annular gap width and slenderness ratio. This paper mainly studies hydraulic transportation characteristics of barreled material pipeline hydraulic transport under different flow conditions, so flow as the main control factor, is discreted as seven, every 10 $\mathrm{m}^{3} / \mathrm{h}$ as a processing. That is flow of $30 \mathrm{~m}^{3} / \mathrm{h}, 40 \mathrm{~m}^{3} / \mathrm{h}, 50 \mathrm{~m}^{3} / \mathrm{h}$, $60 \mathrm{~m}^{3} / \mathrm{h}, 70 \mathrm{~m}^{3} / \mathrm{h}, 80 \mathrm{~m}^{3} / \mathrm{h}$ and $90 \mathrm{~m}^{3} / \mathrm{h}$. Each flow is repeated at least three times and taken the average value. Test piped carriage load $G=1200 \mathrm{~g}$ and $G=1500 \mathrm{~g}$. Slenderness ratio $D / L=$ $0.47,0.40,0.60$.

FIGURE I. THE STRUCTURAL DIAGRAM OF THE PIPED CARRIAGE

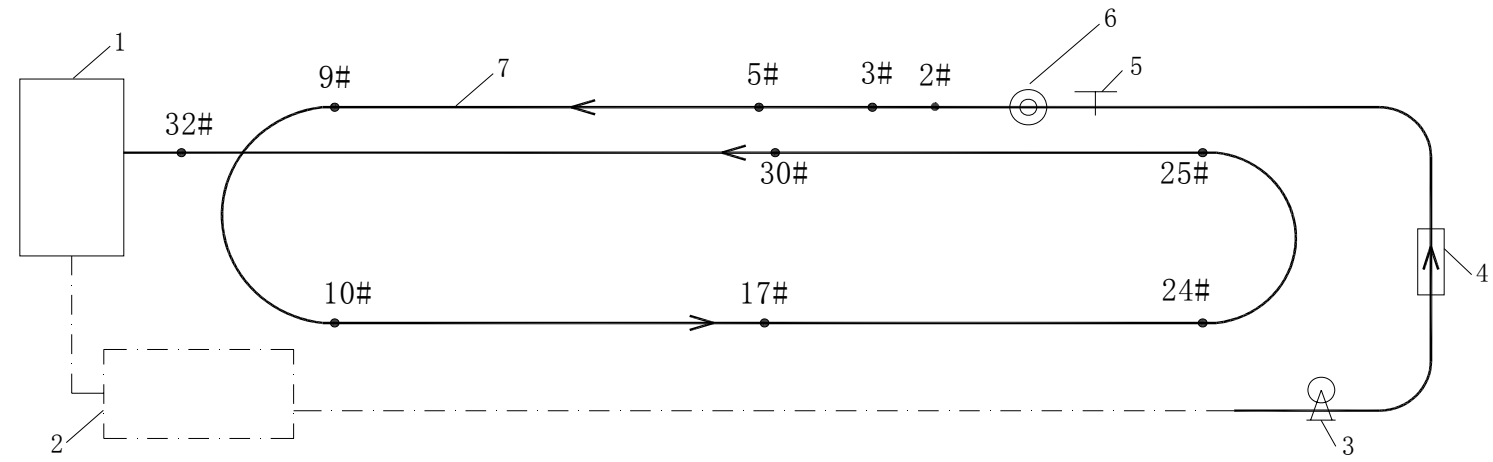

FIGURE II. DIAGRAM OF TEST DEVICE

In Figure II: 1 Receiving device of piped carriage, 2 groundwater reservoir, 3 centrifugal pump, 4 turbine flowmeter, 5 gate valve, 6 release device of piped carriage, 7 organic glass pipeline.

\section{RESUltS AND DiscUSSIONS}

A. Velocity Analysis of Piped Carriage under Different Flow Conditions

Slenderness ratio take to $0.6,0.4$ and 0.47 , while piped carriage load $G=1200 \mathrm{~g}$ and $\mathrm{G}=1500 \mathrm{~g}$. Moving average velocities are illustrated in Figure III.

It can be seen from Figure III, for the same typed piped carriages, when they conveyed the same quality of materials, the average speed of piped carriages increase with flow increase. As to different type, however, the velocity condition

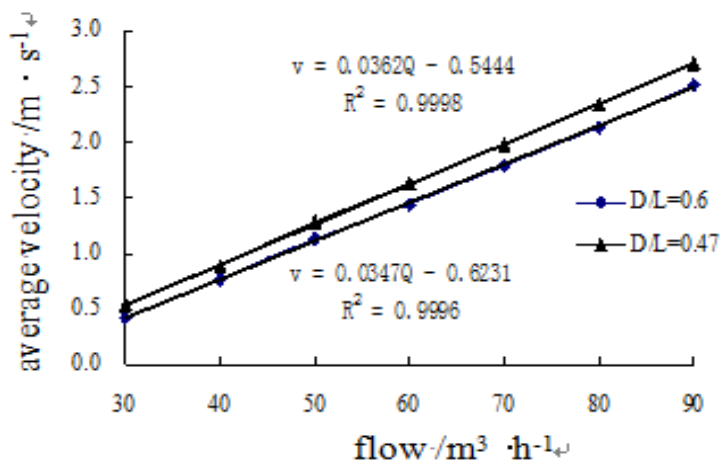

(a) $G=1200 \mathrm{~g}$ is different with the discharge changes though they conveyed the same quality of materials. Moving velocity of piped carriage of slenderness ratio taking to 0.6 is minimum, and slenderness ratio equating to 0.47 is maximum. At the same time, we can see from the figure that the velocity of the fewer loads piped carriage is faster. And from the fitting equation we can see that the piped carriage of slenderness ratio taking to 0.47 (piped carriage with the larger diameter), the load is the same, required for smaller starting velocity; for the same typed piped carriage, the larger load of piped carriage needed the greater starting velocity.

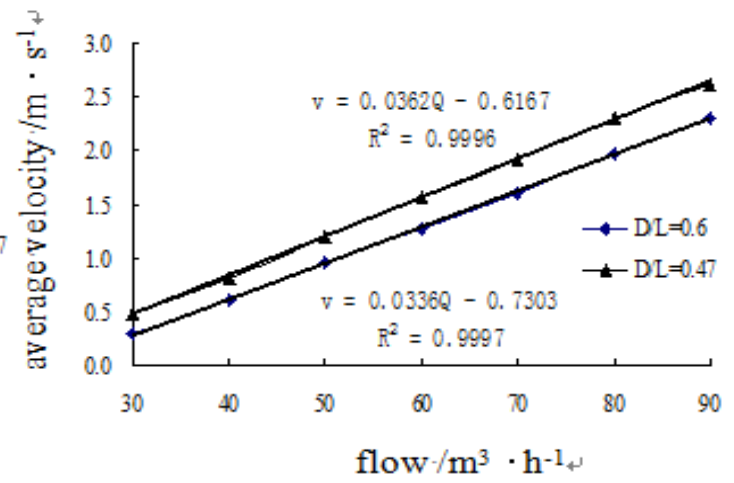

(b) $G=1500 \mathrm{~g}$

FIGURE III. RELATION BETWEEN AVERAGE VELOCITIES OF PIPED CARRIAGE AND FLOWS 


\section{B. Pressure Analysis of the Same Conduit Section with the Flow Changes}

While the load $\mathrm{G}$ is $1500 \mathrm{~g}$, slenderness ratio $\mathrm{D} / \mathrm{L}$ is equate to 0.4 , the pressure change trend of the conduit measuring points with the flow is nearly same during motion process. Figure IV showed the relationship between section pressure of each point and the flow in the end of piped carriage movement.

The figure showed that the pressure values of section of the conduit also increased with the increase of flow. The main reason is that the energy of piped carriage movement derived from the flow. Flow increasing means that the total energy of water increases. By water movement energy equation shows that the total energy comes from two parts of piezometeric level and velocity head. The total energy increases, namely, the piezometeric level and velocity head increasing. Therefore, when the flow rate increases, the pressure value in each section is also increased.

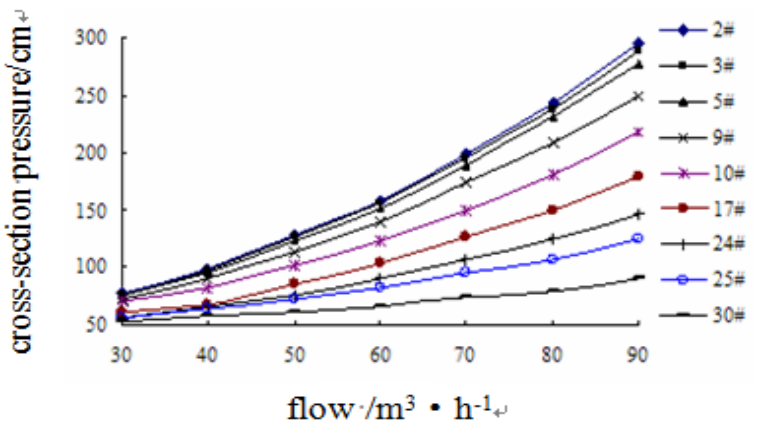

FIGURE IV. RELATION BETWEEN CROSS SECTION PRESSURE AND FLOW

\section{Pressure Analysis of Whole Section with the Flow Changes}

When a piped carriage was moving in pipeline, it ran to different position of conduit at different times. Study on pressure distribution of whole conduit, the slenderness ratio $\mathrm{D} / \mathrm{L}$ is 0.4 and the load of piped carriage $\mathrm{G}$ is $1500 \mathrm{~g}$, at the end of the running. The specific figure shows in Figure V.

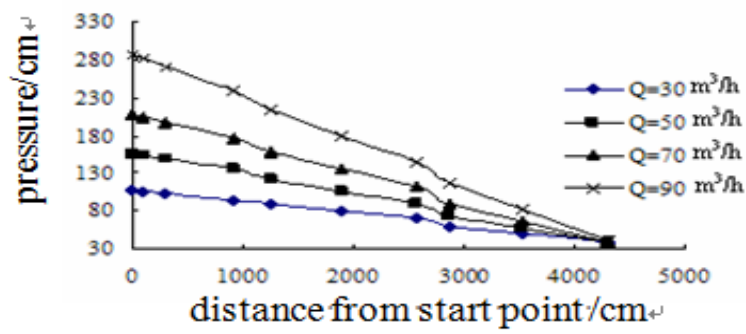

FIGURE V. PRESSURE DISTRIBUTION MAP OF PIPELINE UNDER DIFFERENT FLOW CONDITION

As you can see from Figure $V, 1$ ) the piped carriage running in the same flow conditions, the change trend of pressure distribution curve was basically same, namely the overall pressure distribution of conduit decreases with increasing distance. However, unit length pressure change range was different for different flow. Larger flow, unit length pressure change in value is bigger. 2) According to the change of pressure distribution curve can be roughly divided into three categories: the first category segment pipe section is mainly three straight-line pipe sections. Three straight-line pipe pressure variations are basically the same, roughly the same performance in the change of slope. It mainly caused by the lost of frictional head and part of head for piped carriage running. Second types of pipe section is not the main slope bend (bending section), from the $9 \#$ point to $10 \#$ measuring point. Bend pressure changes in amplitude than the first pipe section increased significantly, and showing changes in its slope is larger than the first. Its reasons in addition to part of head loss for piped carriage running, another reason is mainly due to the influence of the bend flow that not only exists axial motion, but also the circumferential movement. So the change in amplitude of the pipe pressure is bigger than the first. Third types of pipe section is mainly steep bend (oblique bending section), from the $24 \#$ measuring point to $25 \#$ measuring point. The pipe section pressure changes in amplitude are larger than the former two, and showing changes in its slope is bigger than the first two. The main reason is that the pipe section is not only an elbow segment, but climbing tube section. So the pipe pressure variation in the section is most.

\section{CONCLUSIONS}

(1) For the same type of piped carriage, when the load is same, the average speed of the piped carriage increased with discharge increasing, and basically was proportional to the linear relationship.

(2)As the flow increasing, the pressure value of each section and pressure variable increased.

(3)Piped carriage running in the same flow conditions, the pressure distribution curve is basically the same trend .That is the overall pressure distribution within the pipeline decreased with distance increasing. But for different flow, unit length pressure changes under different amplitude. Larger flow, unit length pressure change value is bigger.

\section{ACKNOWLEDGMENTS}

We acknowledge the financial support from Shanxi Natural Science Foundation of China (Grant No.2015011067).

\section{REFERENCES}

[1] Q. Qian, "Major city construction of underground expressway and underground logistics system new ideas to solve the traffic problem in big city of China", Sci. Technol. Rev., 2004,(4):2-5.

[2] Y. Li, X. Sun, Y. Yan, "Hydraulic characteristics of tube-contained raw material hydraulic transportation under the different loads on the piped carriage", Trans. Chin. Soc. Agr. Mach., 2008,39(12):93-96.

[3] Y. Li, X. Sun, Q. Yan, M. Lu, "Research on the piped hydraulic transportation of the different diversion angle", J. Hydrodynamics, Ser.A 2008,23(1):86-89.

[4] Y. Li, X. Sun, F. Li, J. Zhang, "Cyclical slit flow of concentricity under the moving boundary condition", Trans. Chin. Soc. Agr. Mach., 2012,28(2) :174-178.

[5] Y. Lin, F. Wang, "Design of the experimental pipeline system for transporting cylindrical molded Product", Fluid Mach., 2000,28(12): 7-9.

[6] X. Tong, Y. Li, X. Sun, "Experimental system design on the piped hydraulic transportation of tube-contained raw material", Shanxi Water Resour., 2008, (2): 42-43. 